Check for updates

London

Cite this as: $B M J 2020 ; 370: m 3058$ http://dx.doi.org/10.1136/bmj.m3058 Published: 31 July 2020

\section{Covid-19: England had worst excess mortality in Europe in April}

\section{Shaun Griffin}

England had the longest period of excess mortality of any European country during the covid-19 pandemic and an excess mortality peak second only to Spain, new data show. ${ }^{1}$

In the first analysis of its kind the Office for National Statistics compared excess mortality rates throughout Europe from all causes, to avoid the issue of countries recording covid-19 deaths differently. It also looked at the indirect impact of the pandemic, such as non-covid deaths related to delayed access to healthcare.

In comparison with 21 European countries, England had the highest levels of excess mortality in Europe from 3 April to 8 May 2020, 7.5\% more than in the previous five years. Spain had the second highest (6.7\%) and Scotland the third highest (5.1\%). National data for Italy were unavailable.

Spain had the highest peak of excess mortality in the week ending 3 April, when deaths were $139 \%$ higher than expected. England was the second highest and Scotland third highest. The prolonged period of excess deaths in England was what led to it having the highest death rate in Europe.

\section{UK peaks}

Of the UK nations, England's peak excess mortality was highest in the week ending 17 April, at 108\% higher than normal and double its five year average. Scotland had the next highest rate, peaking at $72 \%$ during the week ending 10 April, followed by Wales, at $69 \%$ in the week ending 17 April. Northern Ireland had the lowest level peak, at $48 \%$ during the week ending 24 April.

At the equivalent of local authority level, central Spain and northern Italy had the highest peaks of excess mortality (as high as $847.7 \%$ in Bergamo, Italy), exceeding any part of the UK. Brent, the second most ethnically diverse local authority area in England and Wales, had the UK's highest excess mortality peak at $357.5 \%$.

Edward Morgan of the Office for National Statistics said, "While none of the four UK nations had a peak mortality level as high as Spain or the worst hit local areas of Spain and Italy, excess mortality was geographically widespread throughout the UK during the pandemic, whereas it was more geographically localised in most of western Europe.”

Kevin McConway, emeritus professor of applied statistics at the Open University, said, “One can speculate that [these variations have] something to do with the fact that countries like France and Spain have regions of low population density." He added that data from Germany and from regions within the Netherlands (neither of which were available) "might have helped make more sense of this comparison."

The absence of data from Germany was apparently due to the country's decision to wait to publish very accurate, rather than provisional, data, although the impact of covid-19 has generally been much less there than elsewhere in Europe. This decision "can have advantages, but not when you're trying to make sense of a pandemic that is still occurring," said McConway.

\section{Health divide}

Sheila Bird, former programme lead at the MRC Biostatistics Unit, University of Cambridge, complimented the Office for National Statistics on producing "a substantial and hugely informative report.”

She added, “The analysis of cities' cumulative age and sex standardised excess mortality, reported as percentage of expected deaths to 12 June 2020, is particularly poignant.” Examples were Madrid (26\%), Barcelona (17\%), London (15\%), Birmingham (16\%), Edinburgh (9\%), Glasgow (9\%), Paris (7\%), and Copenhagen (-4.1\%).

Veena Raleigh, senior fellow at the King's Fund, spoke of the unequal impact of covid-19 in the UK, saying, "The pandemic has had ... the greatest toll of lives among older people, more deprived populations and ethnic minority communities, exposing yet again the wide and widening health divide in our population."

She added that it was now "essential to tackle the underlying reasons for [the UK's] stalling life expectancy in recent years-many of which contribute to poor covid-19 outcomes."

\footnotetext{
Office for National Statistics. Comparisons of all-cause mortality between European countries and regions: January to June 2020. Jul 2020. https://www.ons.gov.uk/releases/internationalcomparisonsofeuropeanmortalitydata2020.
}

This article is made freely available for use in accordance with BMJ's website terms and conditions for the duration of the covid-19 pandemic or until otherwise determined by BMJ. You may use, download and print the article for any lawful, non-commercial purpose (including text and data mining) provided that all copyright notices and trade marks are retained. 